\title{
Effect of water supply on leaf area development, stomatal activity, transpiration, and dry matter production and distribution in young olive trees
}

\author{
Maria Gómez-del-Campo \\ Dpto. Producción Vegetal: Fitotecnia, Universidad Politécnica de Madrid, 28040 Madrid, Spain. \\ Email: maria.gomezdelcampo@upm.es
}

\begin{abstract}
Two-year-old olive trees cv. Cornicabra, trained in a central leader form for hedgerow planting, were grown outdoors in 45-L weighing lysimeters to evaluate the effect of water supply on growth and development. Four treatments were established and maintained for 155 days during spring-autumn. Treatment T100 was irrigated to maintain the potting medium close to water-holding capacity by progressive replenishment of consumption that was measured at weekly intervals by weighing and recording drainage. Treatments T80, T60, and T40 received 80, 60, and 40\%, respectively, of the water applied to T100. For these treatments, transpiration and leaf area were measured every fortnight. Dry matter in roots, stems, and leaves was measured at the beginning and end of the experiment. Leaf conductance was measured at 09:00 and 12:00 solar time every fortnight and at c. 2-hourly intervals throughout one day each month. Over the experimental period, T100 produced $0.42 \pm 0.01 \mathrm{~m}^{2}$ leaf area, $319.6 \pm 60.4 \mathrm{~g}$ dry biomass, and transpired $77.5 \pm 1.1 \mathrm{~L}$ water. Water stress significantly reduced leaf area development and dry matter production $(P<0.05)$ in T60 and T40, but not in T80. There was no effect on dry matter partitioning to the various organs of the trees or the roots/aerial part ratio. Leaf conductance was more sensitive to water stress than vegetative growth, with significant differences $(P<0.05)$ established among treatments 3 weeks before differences were observed in transpiration. In autumn, transpiration and leaf conductance increased in all treatments independently of soil water status. Over the experiment, transpiration efficiency (TE, g/L) increased with reduced water supply, with a significant difference $(P<0.10)$ between T100 and both T60 and T40. The study has established that maximum growth of young olive plants can be achieved, without effect on the distribution of biomass between organs, at water supply less than that required to support maximum transpiration.
\end{abstract}

Additional keywords: Olea europaea L., water relations, stomatal response, transpiration efficiency, drought adaptation.

\section{Introduction}

Harvesting is the most expensive operation in Spanish olive cultivation due to the high cost and requirement of labour. In the mid-1990s the possibility of using mechanical harvesters was explored in areas where olive trees and grapevines were both grown. As a result, the first super-high-density olive orchards were planted with trees trained to hedgerows, generally in monocone shape pruned with a central leader, and spaced from $3 \mathrm{~m}$ by $1.3 \mathrm{~m}$ (2564 trees/ha) to $4 \mathrm{~m}$ by $1.5 \mathrm{~m}$ (1667 trees/ha).

The management of these new plantations poses a challenge for producers and researchers to adapt this typical Mediterranean crop that has been long cultivated using dry-farming methods, wide tree spacing $(10 \mathrm{~m}$ by $10 \mathrm{~m}, 100$ trees/ha), and a vaseshaped training system. In order to carry out a rational management of super-high-density olive orchards, it is necessary to identify the physiological responses of olive trees to this new system. The change in the training system incurs an increase in the leaf surface per unit of cultivated surface exposed to the sun and, therefore, an increase in water requirements that in turn demand greater water-use efficiency in the olive-growing region where water is scarce and olive trees compete with other crops for water.

Olive is a crop well adapted to drought conditions by mechanisms that have evolved to both avoid and tolerate drought (Connor and Fereres 2005). The olive tree protects internal metabolism from water stress by closing stomata (Fernández and Moreno 1999), which inevitably decreases photosynthetic rate and, therefore, growth (Moriana et al. 2002). Super-high-density olive orchards come into bearing after 3-4 years while the trees are trained to form a continuous hedgerow to expose maximum leaf surface to the sun. Optimum irrigation management in this phase seeks to minimise water application without reducing vegetative growth. There is a need to be both efficient in the use of water and also to avoid risks of anoxia and fungal infection associated with over-watering.

The objective of this experiment was to establish the growth response of young olive trees to water availability, the effect on dry-matter distribution as a determinant of suitability for planting, and to elucidate the response mechanism to water shortage in terms of leaf-area formation and stomatal response. For this, olive trees were grown in $45-\mathrm{L}$ weighing 
lysimeters under various irrigation regimes. The cultivar used was Cornicabra, the principal cultivar in central Spain, being well adapted to heat and drought in summer and to cold in autumn and winter.

\section{Materials and methods}

This experiment was carried out in 2004 in the open air at the Universidad Politécnica de Madrid in Spain $\left(40^{\circ} 26^{\prime} 36^{\prime \prime} \mathrm{N}, 3^{\circ} 44^{\prime} 18^{\prime \prime} \mathrm{W}\right.$; alt. $\left.590 \mathrm{~m}\right)$. Two-year-old olive trees (cv. Cornicabra) were grown from 27 April to 29 September (155 days) in 45-L weighing lysimeters covered with plastic film to exclude rainfall and eliminate direct evaporation from the soil. The lysimeters were filled with a mixture of peat, organic soil, and perlite $(44: 32: 24)$ over a 50 -mm layer of small stones to facilitate drainage. The substrate had a porosity of $86 \%(\mathrm{v} / \mathrm{v})$, easily available water was $36 \%(\mathrm{v} / \mathrm{v})$, reserve water $5 \%(\mathrm{v} / \mathrm{v})$, and water not easily available was $30 \%(\mathrm{v} / \mathrm{v})$ obtained according to the method described by Gabriels and Verdonck (1992). The olive trees were staked to a height of $2.5 \mathrm{~m}$ and trained in monocones similar to those in super-high-density hedgerow plantations using $4 \mathrm{~m}$ by $1.5 \mathrm{~m}$ tree spacing.

A weather station at the study site registered wind speed and direction, rainfall, temperature, humidity, and global radiation every $30 \mathrm{~min}$ and calculated ETo by the Penman-Monteith method (Allen et al. 1998) from these climatic variables.

The experiment used a completely randomised design with 5 single tree repetitions of 4 irrigation treatments that commenced with all treatments irrigated to drained waterholding capacity. During the experiment, treatment T100 was weighed weekly and irrigated on alternate days to maintain the potting medium close to water-holding capacity while treatments T80, T60, and T40 received 80, 60, and 40\%, respectively, of the water applied to T100. Transpiration was determined gravimetrically at weekly intervals with allowances for drainage in T100 and fortnightly for treatments T80, T60, and T40.

Dry matter distribution was measured in 2 olive trees, similar to those placed in the lysimeters and selected according to median trunk diameter, at the beginning of the experiment. For this, the trees were separated into roots, stems, and leaves, and dried to constant weight in an oven at $80^{\circ} \mathrm{C}$. At the end of the experiment, dry matter was measured similarly in all experimental trees, also separating stems and leaves formed in the current season from those formed previously.

Leaf area of each tree was determined fortnightly as the product of total leaf number per tree and average leaf size, the latter estimated monthly for each treatment by measuring central nerve length of all leaves on one branch per tree. In this case, there was no evidence of variation in leaf size distribution between branches of individual trees. At the end of the cycle, the relationship between central nerve length and leaf area was determined. At the end of the experiment all leaves were removed, counted, and measured with an area meter (Li-3100; Li-Cor, Lincoln, NE, USA), separating the leaves formed in the current from the previous season.

Leaf conductance $\left(g_{1}\right)$ was measured fortnightly at 9:00 and 12:00 UTC with a steady-state porometer (Li-1600; Li-Cor, Lincoln, NE, USA) on healthy leaves exposed to the sun. On 8 September the measurement at 9:00 could not be taken due to cloud. On 16 June, 14 July, 11 August, and 22 September, measurements were made on 7 occasions throughout the day (7:00, 9:00, 10:30, 12:00, 14:00, 16:30, and 18:30 UTC, approx. solar time). On those days, irrigation was delayed until the measurements were completed.

Data were subjected to analysis of variance using MSTAT-C (University of Michigan, USA). Least significant differences $(P<0.05$ and $P<0.10)$ were used to segregate differences among treatment means using Duncan's multiple range test. The biomass partitioning data were transformed before analysis of variance using the arc-sin square-root transformation method to ensure that the data were normally distributed.

\section{Results}

\section{Environmental conditions}

The measurements from the weather station are summarised as daily means in Fig. 1 and the conditions on the days of measurement of leaf conductance are presented in Table 1. During the experimental period, the highest temperature was recorded on 24 July $\left(38^{\circ} \mathrm{C}\right)$ and the lowest on 8 May $\left(2^{\circ} \mathrm{C}\right)$. July was the hottest month with a mean temperature of $24^{\circ} \mathrm{C}$ while May was the coldest $\left(14^{\circ} \mathrm{C}\right)$. Mean solar radiation was $23.8 \mathrm{MJ} / \mathrm{m}^{2}$ with June having the highest $\left(28.7 \mathrm{MJ} / \mathrm{m}^{2}\right)$ and September the lowest $\left(18.1 \mathrm{MJ} / \mathrm{m}^{2}\right)$. Evaporative conditions remained strong throughout the experiment, with a cumulative ETo of $813 \mathrm{~mm}$. June and July presented the highest values $(6.4 \mathrm{~mm} /$ day $)$ and September the lowest $(4.1 \mathrm{~mm} /$ day $)$. The greatest ETo of $7.5 \mathrm{~mm} /$ day occurred on 14 June.

Table 1 shows the weather conditions on the days when diurnal measurements of leaf conductance were made. Peak values of maximum temperature and solar radiation occurred at the end of June, within the first month of the experiment. High temperatures were maintained until the end of July but solar radiation declined gradually through the remaining period of the experiment. The highest values of relative humidity (at 12:00 h) coincided with a period of rainfall in September.

\section{Leaf area}

The seasonal pattern of leaf-area development (Fig. 2) is both a determinant and a consequence of the seasonal pattern of water availability, consumption (transpiration), and water stress. At the beginning of the experiment, mean tree leaf area was $0.09 \pm 0.01 \mathrm{~m}^{2}$, increasing by the end of the period to $0.42 \pm 0.01 \mathrm{~m}^{2}$ in $\mathrm{T} 100$. Treatments $\mathrm{T} 80, \mathrm{~T} 60$, and $\mathrm{T} 40$ developed 93,67 , and $61 \%$, respectively, of the leaf area of T100. Significant differences from the control (T100) in leaf area were established from 21 July in T40 and from 3 August in T60. At the end of the experiment, taken in pairs, T60 and T40 had $66 \%$ of the leaf area of T80 and T100.

Table 2 reports the number, size, and specific leaf mass (SLM, $\mathrm{g} / \mathrm{m}^{2}$ ) of leaves at the end of the experiment. One-year-old leaves were those present at the outset, while current-year leaves were produced during the experimental period. More leaves were produced in T100 and T80 than in T40. At the end of the experiment, T40 had $28 \%$ fewer leaves than T100. The trees lost $15,13,25$, and $38 \%$ of their 1-year-old leaves in T100, T80, T60, and T40, respectively (data not presented). In contrast to the response in leaf number, there was no significant 


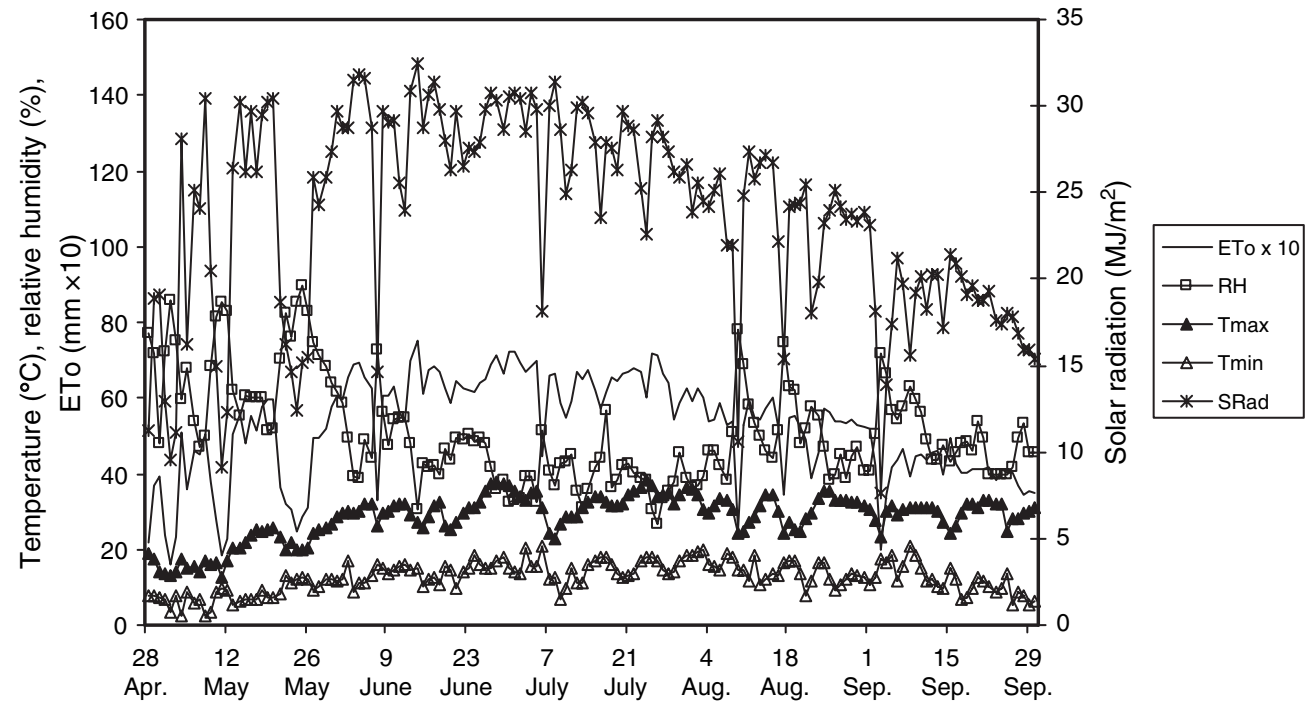

Fig. 1. Daily climatic conditions throughout the experimental period. Maximum and minimum temperature $\left({ }^{\circ} \mathrm{C}\right)$, mean relative humidity $(\%)$, and accumulated solar radiation $\left(\mathrm{MJ} / \mathrm{m}^{2}\right)$ and ETo $(\mathrm{mm} /$ day).

Table 1. Daily ETo, maximum and minimum temperature, solar radiation, and temperature and relative humidity at 12:00 $\mathrm{h}$ solar time on the days of leaf conductance measurements

\begin{tabular}{lrrrrrrrrr}
\hline & 2 June & 16 June & 30 June & 14 July & 28 July & 11 Aug. & 25 Aug. & 08 Sept. & 22 Sept. \\
\hline ETo $(\mathrm{mm} /$ day $)$ & 6.6 & 6.7 & 7.2 & 6.7 & 6.4 & 5.9 & 5.6 & 3.9 & 4.2 \\
Tmax $\left({ }^{\circ} \mathrm{C}\right)$ & 30.1 & 28.8 & 36.9 & 32.3 & 34.7 & 27.1 & 35.4 & 30.9 & 32.9 \\
Tmin $\left({ }^{\circ} \mathrm{C}\right)$ & 17.1 & 12.3 & 14.9 & 15.9 & 13.5 & 11.6 & 12.1 & 20.9 & 10.1 \\
Rsol $\left(\mathrm{MJ} / \mathrm{m}^{2}\right)$ & 28.7 & 30.7 & 30.6 & 29.6 & 27.4 & 27.4 & 24.0 & 15.6 & 19.3 \\
Temp. $12: 00 \mathrm{~h}\left({ }^{\circ} \mathrm{C}\right)$ & 32.7 & 30.3 & 38.0 & 32.7 & 36.6 & 27.3 & 35.2 & 31.9 & 32.6 \\
RH 12:00 $(\%)$ & 26.8 & 24.0 & 15.4 & 25.4 & 22.4 & 32.6 & 16.4 & 36.6 & 23.6 \\
\hline
\end{tabular}

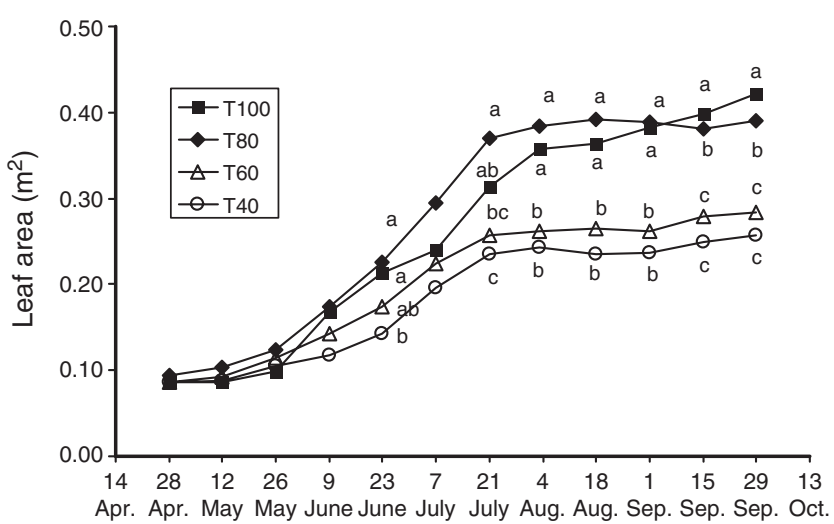

Fig. 2. Development of olive cv. Cornicabra leaf area under various irrigation treatments. T100 was irrigated to maintain the potting medium close to water-holding capacity; T80, T60, and T40 received 80,60 , and $40 \%$ of water applied to T100. Treatments with the same letter are not significantly different by Duncan's test at $P<0.05$.

effect of treatment on leaf size (mean $205 \mathrm{~mm}^{2}$ ), although leaves in T40 were 19\% smaller than those in T100, and leaf rolling was observed in that treatment. These data reveal that the formation of new leaves (leaf number) was more affected by treatment than was leaf expansion.
Table 2. Mean number, area $\left(\mathrm{mm}^{2}\right)$, and specific leaf mass (SLM, $\left.\mathrm{g} / \mathrm{m}^{2}\right)$ of leaves formed in current-year and in 1-year-old leaves in various irrigation treatments

T100 was irrigated to maintain the potting medium close to water-holding capacity; T80, T60, and T40 received 80,60 , and $40 \%$ of water applied to T100. Treatments with the same letter are not significantly different by Duncan's test at $P<0.05$

\begin{tabular}{llccccc}
\hline Treatment & \multicolumn{2}{c}{ Leaf number } & \multicolumn{2}{c}{ Leaf size } & \multicolumn{2}{c}{ SLM } \\
& Current & 1-year & Current & 1 -year & Current & 1-year \\
\hline T100 & $1554 \mathrm{a}$ & 272 & 235 & 254 & $221 \mathrm{~b}$ & 244 \\
T80 & $1616 \mathrm{a}$ & 301 & 196 & 257 & $231 \mathrm{ab}$ & 252 \\
T60 & $1373 \mathrm{ab}$ & 244 & 181 & 208 & $243 \mathrm{a}$ & 253 \\
T40 & $1112 \mathrm{~b}$ & 204 & 190 & 213 & $239 \mathrm{a}$ & 258 \\
\hline
\end{tabular}

Specific leaf mass (SLM) of leaves increased significantly in response to restricted water availability, from $225 \pm 12 \mathrm{~g} / \mathrm{m}^{2}$ in $\mathrm{T} 100$ to $243 \pm 7 \mathrm{~g} / \mathrm{m}^{2}$ in T60 and T40 (Table 2). Leaves $>1$-year old $\left(252 \mathrm{~g} / \mathrm{m}^{2}\right)$ had greater SLM than leaves formed during the experiment $\left(221-243 \mathrm{~g} / \mathrm{m}^{2}\right)$.

\section{Transpiration}

The seasonal patterns of transpiration per tree and per leaf area, calculated for weekly and fortnightly periods, are presented, along with ETo, in Fig. 3. Since treatments were fully watered 

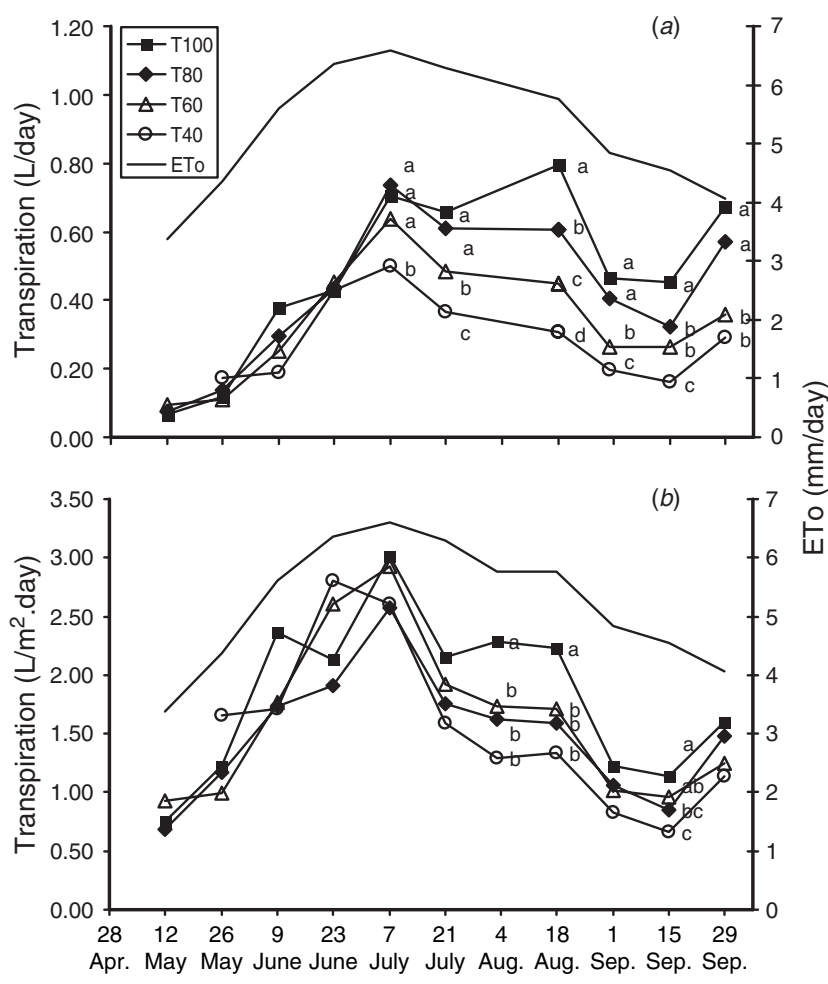

Fig. 3. Daily transpiration of olive trees $\mathrm{cv}$. Cornicabra in various irrigated treatments: $(a)$ transpiration per tree; $(b)$ transpiration per unit leaf area. T100 was irrigated to maintain the potting medium close to water-holding capacity; T80, T60, and T40 received 80,60 , and $40 \%$ of water applied to T100. Treatments with the same letter are not significantly different by Duncan's test at $P<0.05$.

at the beginning of the experiment, no significant differences in transpiration were observed in the stress treatments until the easily available water $(16.2 \mathrm{~L})$ had been consumed. Thus, treatment effects on tree transpiration (Fig. 3a) appeared successively: first in T40 on 7 July, followed by T60 on 21 July, and finally by T80 on 18 August. Transpiration then decreased until 29 September when a sharp increase was observed in all treatments. Maximum transpiration per tree $(0.7-0.8 \mathrm{~L} /$ day $)$ was observed in July and August responding to increasing leaf area (Fig. 2) rather than coinciding with maximum values of ETo (6.0-6.5 mm/day).

In contrast, when evaluated against leaf area (Fig. 3b), maximum transpiration was reached between mid-June and mid-July, earlier than for tree transpiration (Fig. 3a), and coinciding with maximum ETo. There were no differences among treatments to that time. T100 achieved the greatest transpiration, nearly $3.0 \pm 0.4 \mathrm{~L} / \mathrm{m}^{2}$.day, at the beginning of July and maintained a higher rate than the other treatments almost to the end of the experiment when transpiration increased suddenly in all treatments. Significant differences in transpiration were recorded among treatments on 3 August, 18 August, and 15 September, when transpiration was significantly greater in T100 than in T60 and T40.

Cumulative tree transpiration over the experimental period was significantly different among treatments (Table 3).
Table 3. Effect of water supply on transpiration per tree $(L)$ over the experimental period, the mean transpiration per unit leaf area $\left(\mathrm{L} / \mathrm{m}^{2}\right.$.day) calculated from progressive measurements of transpiration and tree leaf area, and transpiration efficiency ( $g$ biomass $/ L$ ) in production of biomass

T100 was irrigated to maintain the potting medium close to water-holding capacity; T80, T60, and T40 received 80,60 , and $40 \%$ of water applied to T100. Treatments with the same letter are not significantly different by Duncan's test at $P<0.05$

\begin{tabular}{lccc}
\hline Treatment & $\begin{array}{c}\text { Tree } \\
\text { transpiration }\end{array}$ & $\begin{array}{c}\text { Mean transp./ } \\
\text { leaf area }\end{array}$ & $\begin{array}{c}\text { Transpiration } \\
\text { efficiency }\end{array}$ \\
\hline T100 & $77.5 \mathrm{a}$ & $1.958 \mathrm{a}$ & $3.868 \mathrm{~b}$ \\
T80 & $67.0 \mathrm{~b}$ & $1.704 \mathrm{ab}$ & $4.248 \mathrm{ab}$ \\
$\mathrm{T} 60$ & $53.4 \mathrm{c}$ & $1.715 \mathrm{ab}$ & $4.347 \mathrm{a}$ \\
$\mathrm{T} 40$ & $40.7 \mathrm{~d}$ & $1.467 \mathrm{~b}$ & $4.466 \mathrm{a}$ \\
\hline
\end{tabular}

Treatment T100 consumed $77.5 \pm 1.1 \mathrm{~L}$, while T80, T60, and T40 consumed $87 \%, 69 \%$, and $53 \%$ of T 100 , respectively. On the basis of leaf area, a significant difference was established only between extreme treatments, T100 and T40, this reflecting the variation in leaf area within treatments. Mean daily transpiration for T100 was $2.0 \pm 0.3 \mathrm{~L} / \mathrm{m}^{2}$.day, falling to $1.5 \pm 0.2 \mathrm{~L} / \mathrm{m}^{2}$.day in T40.

\section{Biomass and partitioning}

At commencement of the experiment in April the trees had $50 \pm 6 \mathrm{~g}$ dry biomass that by September had increased to $369.6 \pm 60.4 \mathrm{~g}$ in T100 (Table 4). In April, $20 \pm 4 \mathrm{~g}, 9 \pm 1 \mathrm{~g}$, and $21 \pm 3 \mathrm{~g}$ was in roots, leaves, and stems, repectively. By the end of the experiment, tree biomass was significantly reduced from the control (T100) in T60 and T40 but not in T80. Biomass in T60 and T40 was 75 and 63\%, respectively, of T100.

Significant differences in the distribution of biomass in component organs of roots, stems, and leaves were observed among treatments (Table 4). The greatest proportion of biomass both at the beginning (43\% in April) and at the end of the season (50\% in September) was in stems. In September, $66 \%$ of aerial dry matter was found in stems of which $74 \%$ was in stems formed before the start of the experiment. Dry matter content in these stems increased from $21.4 \mathrm{~g}$ in April to $115.7 \mathrm{~g}$ in September, while dry matter content of new stems was $40.3 \mathrm{~g}$ in September. Dry matter content in stems was significantly different among irrigation treatments. Leaf mass was significantly greater in T100 and T80 than in T60 and T40, while root mass was significantly greater in T100 and T80 than in T40. In all treatments, leaves were the organs that showed the greatest increase in biomass. Over all treatments, biomass in leaves, stems, and roots increased 9, 7, and 3 times, respectively. Root/aerial dry matter ratio (Table 4) and biomass partitioning among organs (data not presented) were not significantly affected by irrigation treatments.

\section{Leaf conductance}

Two sets of measurements are available to evaluate the seasonal and diurnal responses of stomata, respectively. The first set, presented in Fig. 4, records the leaf conductance $\left(\mathrm{g}_{1}\right)$ at 09:00 and 12:00 $\mathrm{h}$ at fortnightly intervals during the experiment. These data reveal a common trend of decline during the summer months 
Table 4. Dry matter contents $(\mathrm{g})$ in trees at the end of the experiment and its distribution in roots, stems, and leaves, together with the relationship between root/aerial dry matter content $(\mathrm{g} / \mathrm{g})$ in various irrigation treatments

T100 was irrigated to maintain the potting medium close to water-holding capacity; T80, T60, and T40 received 80,60 , and $40 \%$ of water applied to T100. Treatments with the same letter are not significantly different by Duncan's test at $P<0.05$

\begin{tabular}{lllccc}
\hline & Roots & Stems & Leaves & Total biomass & $\begin{array}{r}\text { Root/aerial } \\
\text { dry matter }\end{array}$ \\
\hline T100 & $80.8 \mathrm{a}$ & $190.7 \mathrm{a}$ & $98.1 \mathrm{a}$ & $369.6 \mathrm{a}$ & 0.272 \\
T80 & $76.0 \mathrm{ab}$ & $169.2 \mathrm{~b}$ & $89.8 \mathrm{a}$ & $334.9 \mathrm{a}$ & 0.293 \\
T60 & $63.2 \mathrm{bc}$ & $146.5 \mathrm{c}$ & $72.1 \mathrm{~b}$ & $281.8 \mathrm{~b}$ & 0.288 \\
T40 & $53.4 \mathrm{c}$ & $117.5 \mathrm{~d}$ & $61.1 \mathrm{~b}$ & $232.0 \mathrm{c}$ & 0.293 \\
\hline
\end{tabular}

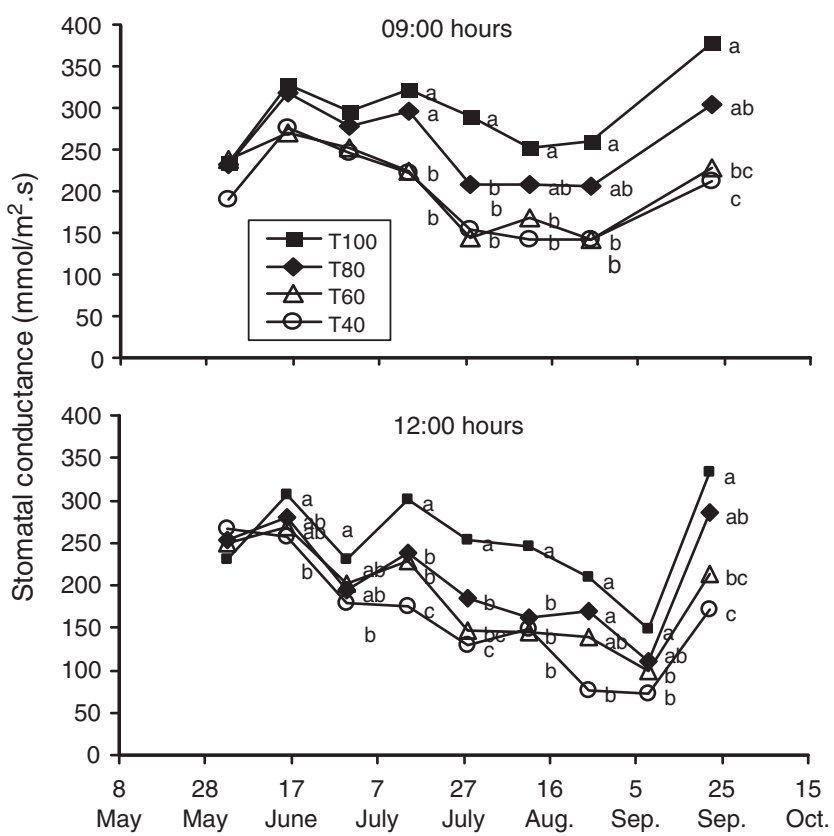

Fig. 4. Leaf conductance at 09:00 and 12:00 $\mathrm{h}$ in olive trees cv. Cornicabra in various irrigation treatments. T100 was irrigated to maintain the potting medium close to water-holding capacity; T80, T60, and T40 received 80 , 60 , and $40 \%$ of water applied to T100. Treatments with the same letter are not significantly different by Duncan's test at $P<0.05$.

that is more marked at 12:00 than at 09:00 h. They also show that treatment differences were established 3 weeks earlier than were differences in leaf area (Fig. 2). Significant differences were observed among treatments after 14 July at 9:00 and after 19 June at 12:00 h. After these dates, $g_{1}$ was significantly greater in T100 than in T40. Significant differences in $g_{1}$ were only found between T60 and T40 on 14 July at 12:00 h and between T80 and T60 on 14 July at 09:00 h. Maximum values of $\mathrm{g}_{1}$ were around $379 \mathrm{mmol} / \mathrm{m}^{2} . \mathrm{s}$, falling to $70 \mathrm{mmol} / \mathrm{m}^{2} . \mathrm{s}$ in T40 towards the end of the summer. Mean $\mathrm{g}_{1}$ at 09:00 $\mathrm{h}$ throughout the season was $295 \pm 42,256 \pm 18,208 \pm 15$, and $198 \pm 35 \mathrm{mmol} / \mathrm{m}^{2} . \mathrm{s}$ in $\mathrm{T} 100, \mathrm{~T} 80, \mathrm{~T} 60$, and T40, respectively, while at 12:00 $\mathrm{h}$ the corresponding values were $251 \pm 34,209 \pm 14,188 \pm 9$, and $164 \pm 23 \mathrm{mmol} / \mathrm{m}^{2}$.s. Combining both times of measurement, mean $\mathrm{g}_{1}$ was 85,73 , and $66 \%$ of $\mathrm{T} 100$ in $\mathrm{T} 80, \mathrm{~T} 60$, and $\mathrm{T} 40$, respectively.

A significant feature of these data is the recuperation of $\mathrm{g}_{1}$ in all treatments at the end of the season. Leaf conductance rose then to $400 \mathrm{mmol} / \mathrm{m}^{2}$.s in T100, its highest value recorded in this experiment. Temperature and evaporative demand (ETo) were less than during the previous measurements so the data suggest some internal plant response controlling this aspect of behaviour.

The diurnal measurements of $g_{1}$ presented in Fig. 5 confirm aspects of the fortnightly data. The diurnal trends show the same pattern of early development of stress in T40, followed by gradually increasing stress in the other treatments as the season progressed. Differences in $\mathrm{g}_{1}$ became greater between treatments as the season progressed. On 16 June, $g_{1}$ in T100 was significantly greater than in T40 at 12:00, 16:30, and 18:30 h. On 14 July, significant differences were observed among treatments throughout the day except at 09:00 h. Significantly greater $\mathrm{g}_{1}$ was observed in T100 than in T40. After 10:30 h, $\mathrm{g}_{1}$ in T80 was not significantly different from that in T60, while after 12:00 h, $\mathrm{g}_{1}$ in T40 was significantly smaller than in the rest of the treatments, except at the end of the day. On 11 August, $g_{1}$ in T100 was significantly greater than in T40 from $09: 00 \mathrm{~h}$ and significantly greater than in T60 from 12:00 h onwards. After 12:00 h, no significant differences were found among T80, T60, and T40. On 22 September, the greatest $g_{1}$ was registered and the greatest differences were found among treatments. Leaf conductance was significantly greater in T100 than in T60 and T40 at all times of measurement.

The data also showed another aspect of stomatal response of olive to water stress and environment in the form of a common diurnal trend that persisted throughout the season in all treatments. Even when water was readily available and transpiration demand was low due to small leaf area (e.g. 18 June), $\mathrm{g}_{1}$ attained maximum values in the morning with declining values in the afternoon. As the stress developed, the pattern was maintained but the time of peak $\mathrm{g}_{1}$ occurred earlier in stressed treatments. Thus all treatments attained maximum $\mathrm{g}_{1}$ at 10:00-11:00 $\mathrm{h}$ at the start of the season, but by August, maximum $g_{1}$ for $\mathrm{T} 60$ and $\mathrm{T} 40$ was recorded on the first occasion of measurement (07:00 h).

\section{Transpiration efficiency (TE)}

The relationship between biomass production and total transpiration defines TE over the experimental period (Table 3). The value of this relationship reveals a gradual increase in TE with restricted water supply, with significant differences established $(P<0.10)$ between T100 and extreme treatments T60 and T40.

\section{Discussion}

The observations of growth and transpiration reveal that maximum growth of olive cv. Cornicabra can be achieved at a water supply less than required to support maximum transpiration. The transpiration of trees grown without water stress (T100) during 155'days from spring to summer amounted to $77.5 \pm 1.1 \mathrm{~L}$, which is low compared with ETo and the area $\left(6 \mathrm{~m}^{2}\right)$ allocated to each tree. Irrigation at T80 that sustained a total seasonal transpiration of $67.0 \mathrm{~L} /$ tree maintained the same 

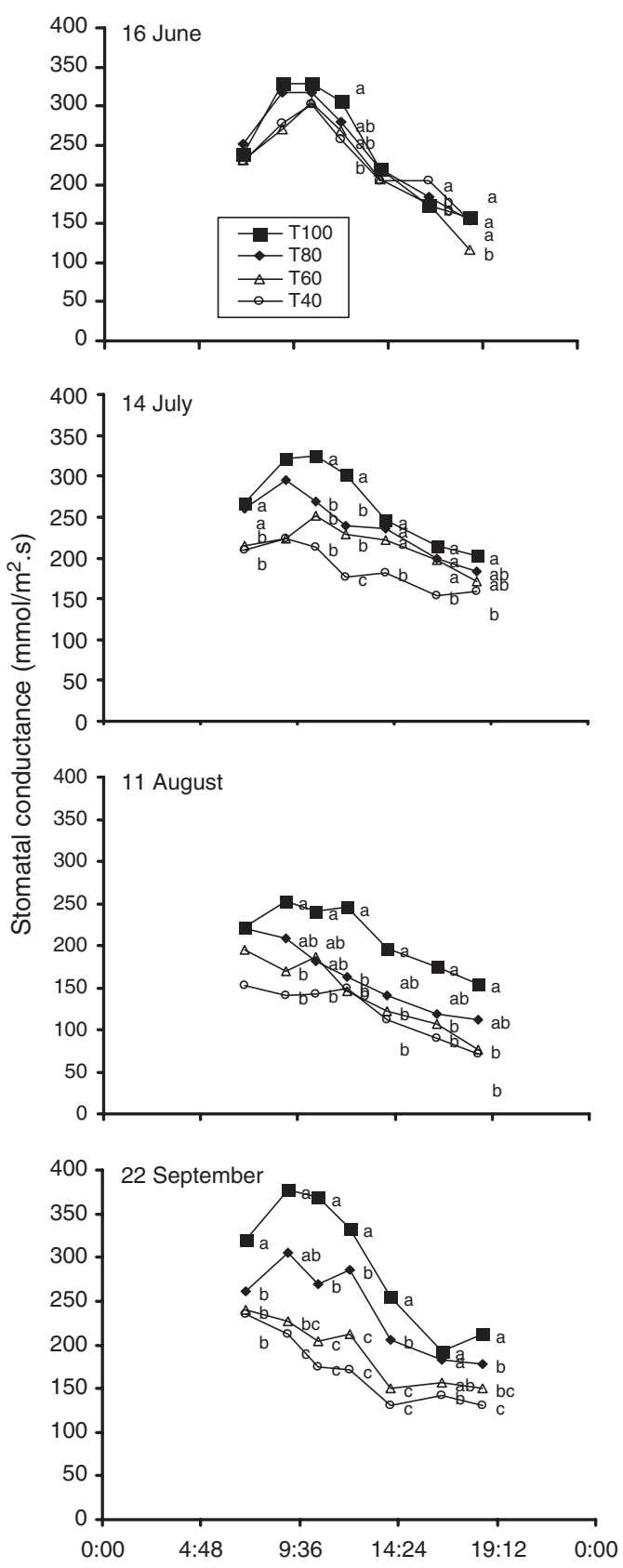

Fig. 5. Leaf conductance throughout the day on 19 June, 14 July, 11 August, and 22 September in olive trees cv. Cornicabra in various irrigation treatments. T100 was irrigated to maintain the potting medium close to water-holding capacity; T80, T60, and T40 received 80,60 , and $40 \%$ of water applied to T100. Treatments with the same letter are not significantly different by Duncan's test at $P<0.05$.

leaf area (Fig. 2) and accumulated the same final biomass (Table 4) as T100. Final leaf area $\left(0.42 \pm 0.01 \mathrm{~m}^{2}\right)$ (Fig. 2) and final dry matter in T100 (369.6 $\pm 60.4 \mathrm{~g})$ (Table 4) are comparable with those of similar aged trees of other cultivars observed in the field by Nuzzo et al. (1997) and Mariscal et al. (2000). It is an important finding of this work that water supply limited to $80 \%$ of potential transpiration can also maintain maximum growth in young actively growing trees with a dominance of new leaves well exposed to the sun. Management can use this information to avoid over-watering during this formation phase because that introduces risks of poor growth under anaerobic conditions and of establishing diseases such as Verticillium in planting stock. The data also define the cost in terms of growth at suboptimal water supply. Irrigation at T60 reduced transpiration to $69 \%$ but growth to $75 \%$. At T40, the corresponding values were $53 \%$ and $63 \%$, respectively.

Olive has a range of avoidance and tolerance mechanisms to assist productivity and survival in low-water environments (Connor and Fereres 2005). Although the classic partitioning response of greater root/shoot ratio that improves water balance (Kozlowski and Pallardy 1997) was not observed in this experiment, important responses in rate of leaf formation, leaf morphology, and leaf conductance led to shifts in the relationship between transpiration and growth. Leaf size and SLM recorded in this study with mean values of $205 \pm 37 \mathrm{~mm}^{2}$ and $237 \pm 12 \mathrm{~g} / \mathrm{m}^{2}$ are consistent with many other observations in the olive literature, bearing in mind that both parameters exhibit variation among cultivars and responses to growing conditions (Bosabalidis and Kofidis 2002; Hagidimitriou and Pontikis 2005). Under extreme stress, leaf size is known to decline, SLM to increase (Abdel-Razik 1989; Fernández and Moreno 1999), and finally leaves to curl and fall. In this experiment, with its controlled development of stress, leaf size did not vary among treatments, SLM was greater in T60 and T40 than in the control (Table 2), and while leaf fall of 1-yearold leaves did increase with water shortage, the effect was small so the development of leaf area was dominated by the production and expansion of new leaves during the experiment.

The regular measurements of stomatal conductance $\left(g_{1}\right)$ that were made throughout the experiment reveal important aspects of the drought resistance of olive (Figs 4 and 5). First, the usual levels of $\mathrm{g}_{1}$ (range $234-378 \mathrm{mmol} / \mathrm{m}^{2} . \mathrm{s}$ ) in well watered olive are low by comparison with other horticultural tree species (Connor and Fereres 2005) but also with the high values at 9:00 UTC (300-444 $\left.\mathrm{mmol} / \mathrm{m}^{2} . \mathrm{s}\right)$ that were observed in autumn (see below). Second, stomatal closure was the first response to water shortage observed in this experiment. Reduction in $\mathrm{g}_{1}$ was observed 3 weeks before effects on leaf area development were recorded. Leaf conductance at noon fell gradually from 250 to $72 \mathrm{mmol} / \mathrm{m}^{2}$.s in T60 and T40, as the stress deepened. Third, the daily behaviour of stomata, more open in the morning than in the afternoon, is consistent with the optimisation theory of stomatal control that maximises TE (Cowan 1982) during the diurnal cycle. Olive, with low internal conductance to $\mathrm{CO}_{2}$ due to leaf anatomy, is a good candidate for greater TE with stomatal closure. The effect is seen in these data as TE increased gradually with water restriction and was significantly different $(P<0.10)$ between extreme treatments (Table 3$)$. The consequence is the potential for water saving without growth penalty in commercial practice.

The fortnightly observations also detected an unexpected marked increase in $g_{1}$ in autumn (August-September) (Fig. 4). That response, inferred from a greater transpiration rate at the leaf level, was also evident in the plant transpiration data shown in Fig. 3. Hagidimitriou and Pontikis (2005) have recently reported a similar response in $\mathrm{g}_{1}$ in all 5 Greek cultivars of 
olive they studied, also grown outdoors in pots. In that case, all plants were well watered, whereas in the present experiment, the response was also evident, without re-watering, in the lowwater-supply treatments. There is no obvious explanation for this response, which takes $g_{1}$ in olive, in both studies, to the highest values (c. $450 \mathrm{mmol} / \mathrm{m}^{2} . \mathrm{s}$ in the Greek study) reported in the literature. The response cannot be readily associated with changes in temperature or humidity but rather seems to be due to a modification in tree physiology, perhaps to increased water uptake due to root activity or greater xylem conductivity within the plant. This stomatal response is apparently distinct from that reported by Moriana et al. (2003) in a field orchard in autumn. There, a marked increase in $\mathrm{g}_{1}$ could be explained as a response to sudden resumption of soil water supply when substantial rainfall terminated an extended dry summer-autumn period. The response observed here and in the Hagidimitriou and Pontikis (2005) study warrants further investigation.

\section{Acknowledgments}

I express my gratitude to Prof. David J. Connor for suggestions on the manuscript and to José Ramón Lissarrague for lending some research equipment. I gratefully thank Beatriz Suarez, Pilar Tejela, and Francois Camsusou for field data collection. This project was supported by Universidad Politécnica de Madrid (Project A0409).

\section{References}

Abdel-Razik M (1989) A model of the productivity of olive trees under optional water and nutrient supply in desert conditions. Ecological Modelling 45, 179-204. doi: 10.1016/0304-3800(89)90081-1

Allen RG, Pereira LS, Raes D, Smith M (1998) 'Crop evapotranspiration. Guidelines for computing crop water requirements.' FAO Irrigation and Drainage Paper 56. (FAO: Rome)

Bosabalidis AM, Kofidis G (2002) Comparative effects of drought stress on leaf anatomy of two olive cultivars. Plant Science 163, 375-379. doi: 10.1016/S0168-9452(02)00135-8
Connor D, Fereres E (2005) The physiology of adaptation and yield expression in olive. Horticultural Reviews 31.

Cowan IR (1982) Water-use and optimization of carbon assimilation. In 'Encyclopedia of plant physiology. New series, Vol. 12B'. (Eds OL Lange, PS Nobel, CB Osmond, H Ziegler) pp. 589-613. (Springer-Verlag: New York)

Fernández JE, Moreno F (1999) Water use by the olive tree. Journal of Crop Production 2, 101-162. doi: 10.1300/J144v02n02_05

Gabriels R, Verdonck O (1992) Reference method for the determination of physical properties of plant substrates. Acta Horticulturae 302, 169-179.

Hagidimitriou M, Pontikis CA (2005) Seasonal changes in $\mathrm{CO}_{2}$ assimilation in leaves of five major Greek olive cultivars. Scientia Horticulturae 104, 11-24. doi: 10.1016/j.scienta.2004.07.011

Kozlowski TT, Pallardy SG (1997) 'Physiology of woody plants.' (Academic Press: New York)

Mariscal MJ, Orgaz F, Villalobos FJ (2000) Radiation-use efficiency and dry matter partitioning of a young olive (Olea europaea) orchard. Tree Physiology 20, 65-72.

Moriana A, Orgaz F, Pastor M, Fereres E (2003) Yield responses of a mature olive orchard to water deficits. Journal of the American Society for Horticultural Science 128, 425-431.

Moriana A, Villalobos FJ, Fereres E (2002) Stomatal and photosynthetic responses of olive (Olea europaea L.) leaves to water deficits. Plant, Cell \& Environment 25, 395-405. doi: 10.1046/j.0016-8025.2001.00822.x

Nuzzo V, Xiloyannis C, Dichio B, Montanaro G, Celano G (1997) Growth and yield in irrigated and non-irrigated olive trees cultivar Coratina over four years after planting. In '2nd International Symposium on Irrigation of Horticultural Crops'. Vols 1 and 2. pp. 75-82. (International Society Horticultural Science: Louvain, Belgium)

Manuscript received 31 May 2006, accepted 8 March 2007 